\title{
"What Does it Mean to be Trauma-Informed?": A Mixed-Methods Study of a Trauma-Informed Community Initiative
}

\author{
Robey B. Champine $\mathbb{1}^{1,2} \cdot$ Erin E. Hoffman $\mathbb{1}^{2,3} \cdot$ Samantha L. Matlin ${ }^{2,4} \cdot$ Michael J. Strambler $\mathbb{B}^{2} \cdot$ \\ Jacob Kraemer Tebes $\mathbb{1}^{2}$
}

Accepted: 21 November 2021 / Published online: 7 January 2022

(c) The Author(s), under exclusive licence to Springer Science+Business Media, LLC, part of Springer Nature 2021

\begin{abstract}
Trauma during childhood has the potential to adversely affect one's physical, cognitive, emotional, and social development across the life span. However, the adverse effects of trauma can be prevented and mitigated through holistic services and supports that are trauma-informed. The Pottstown Trauma-Informed Community Connection (PTICC) is a community-based initiative that aims to build a trauma-informed community through training diverse stakeholders (e.g., school staff, providers, community leaders, parents) on the potential signs and symptoms of child trauma and how to create safe physical and emotional environments for children and families. This paper presents findings from a mixed-methods study of education and community partners' $(N=82)$ experiences in PTICC and their understandings of what it means to become traumainformed. Paired sample $t$-tests found significant changes in participants' beliefs about trauma-informed practice, but there were no changes in participants' perceptions of the impacts of PTICC on their use of trauma-informed practices and supports. Focus groups with education $(n=6)$ and community $(n=5)$ partners found that participants regarded being "trauma-informed" as reframing one's perspective, being more self-reflective, acquiring skills to respond more effectively to others who have experienced trauma, and having a sense of hope for the future. Findings also revealed perceived benefits of trauma training and challenges associated with getting others to buy-in to trauma-informed work. Potential methodological considerations for future community-engaged research in building trauma-informed communities are discussed. These considerations include the need to address ceiling effects, disaggregate data, and mitigate challenges associated with participant engagement.
\end{abstract}

Keywords Trauma-informed practice $\cdot$ Adverse childhood experiences $\cdot$ Community-based participatory research $\cdot$ Mixedmethods research $\cdot$ Methodology

\section{Highlights}

- The adverse effects of trauma can be prevented and mitigated through holistic services that are trauma-informed.

- Participation in PTICC was linked to enhanced understanding of what it means to be "trauma-informed".

- This mixed-methods study raised methodological considerations for future research in building trauma-informed communities.

Robey B. Champine

champi74@msu.edu

1 Division of Public Health, Michigan State University College of Human Medicine, Flint, MI 48502, USA

2 Division of Prevention and Community Research, Yale School of Medicine, New Haven, CT 06511, USA

3 College of Science and Health, Department of Psychology, DePaul University, Chicago, IL 60604, USA

4 The Scattergood Foundation, 1501 Cherry Street, Philadelphia, PA 19102, USA
Experiences of trauma are ubiquitous and linked to a host of adverse health outcomes across the life span, including chronic diseases, depression, and substance use (Chang et al., 2020; Sowder et al., 2018). Approximately one half of all U.S. adults report at least one traumatic event in their lives (National Institute of Mental Health [NIMH], 2017), and more than two thirds of children report at least one adverse childhood experience (ACE) by the age of 16 (Substance Abuse and Mental Health Services Administration [SAMHSA], 2020). Trauma, including traumatic 
stress, is defined as an event, series of events, or set of circumstances that an individual or group experiences as physically and/or emotionally harmful (SAMHSA, 2014). These events and circumstances include poverty, violence, discrimination, homelessness, natural disasters, and, as underscored by Coronavirus Disease 2019 (COVID-19), pandemics (Bridgland et al., 2021; Krystal et al., 2021; SAMHSA, 2014). Trauma disproportionately burdens populations of color, indigenous communities, and members of sexual minority groups, thus necessitating a traumainformed social justice response (SAMHSA 2014; Scheer and Poteat, 2018; Stolbach \& Anam, 2017).

\section{Adopting a Multilevel Trauma-Informed Approach}

The adverse effects of trauma can be prevented and mitigated through holistic services and supports that are traumainformed and fit diverse clinical, organizational, and community settings (Middleton et al., 2019; Temkin et al., 2020). A trauma-informed approach is characterized by a realization of the widespread impacts of trauma and various pathways to recovery; the recognition that experiences of trauma may be accompanied by specific signs and symptoms; a comprehensive and integrative response; and efforts to prevent re-traumatization (Harris \& Fallot, 2001; SAMHSA, 2014; Tebes et al., 2019). This approach emphasizes safety; trustworthiness and transparency; peer support; collaboration and mutuality; empowerment, voice, and choice; and addresses cultural, historical, and gender issues (SAMHSA, 2014).

Of note, there are different ways in which scholars have conceptualized trauma-informed work across disciplines. "Trauma-specific services" are interventions that seek to address trauma symptoms or other responses individuals and groups have after they have experienced a trauma (e.g., Trauma-Focused Cognitive Behavioral Therapy [TF-CBT)] (DeCandia et al., 2014). In contrast, "trauma-informed care" refers to a universal framework that involves making changes to programs, policies, and practices to understand, identify, and address trauma (DeCandia et al., 2014; Hanson et al., 2018). These efforts include workforce development (e.g., training staff to understand trauma and its potential impacts), the delivery of evidence-based trauma-focused services, and organizational practices (e.g., promoting a culture of safety, enhanced collaboration) (Hanson et al., 2018). These practices can collectively be viewed as representing a trauma-informed approach that encompasses awareness, understanding, and action (Hanson et al., 2018). As described by Hanson et al., (2018), being "traumainformed" can take different forms depending on a person's role (e.g., teacher, service provider, law enforcement professional, parent). Consistent with this work, scholarship has emphasized the need for a trauma-informed approach that is multilevel and prioritizes population health through prevention and promotion programs, policies, and practices, given the pervasive nature of trauma and its potentially harmful impacts on individuals, groups, and communities (Magruder et al., 2017; Matlin et al., 2019; Tebes et al., 2019).

Matlin et al. (2019) proposed a three-dimensional model that presents different components of trauma-informed practice. The model differentiates between two types of approaches that at a practice can adopt: treatment/healing or prevention/promotion, consistent with previous research on the use of risk prevention and health promotion approaches to trauma (Bloom, 2013; Matlin et al., 2019). Whereas a treatment/healing approach is focused on reducing signs and symptoms of distress in the aftermath of a traumatic event, a program, policy, or practice that adopts a prevention/promotion approach seeks to reduce the likelihood of a disruption from occurring in the first place following a traumatic event (Matlin et al., 2019). Next, the model specifies the socio-ecological level at which such efforts can be directed: individual (e.g., personal attitudes, beliefs, behaviors), relational (e.g., family, couple, peer), organizational (e.g., schools, workplaces, neighborhoods), or community/ system (e.g., cities, towns, child welfare and educational systems) (Matlin et al., 2019). Finally, the model specifies the intervention target of such efforts. Whereas traumaspecific efforts target individuals and groups who have experienced trauma (e.g., trauma-specific services), universal interventions emphasize providing trauma-informed care to all individuals in a setting or population (e.g., school district). This model elucidates a range of responses to adversity, with priority given to universal interventions that emphasize risk reduction and health promotion and are implemented at the community/systems level; these interventions offer the greatest potential for population health impact (Bloom, 2013; Matlin et al., 2019; Tebes et al., 2019). The intervention presented in this article, the Pottstown Trauma-Informed Community Connection (PTICC) (n.d.), is an example of such a universal intervention, as it engaged parents, teachers, providers, and leaders throughout a community in efforts to understand childhood trauma and its widespread effects and how to implement programs, polices, and practices that aim to prevent risk and promote health.

\section{Trauma-Informed Community-Based Interventions}

A growing body of research has examined the processes involved in building a community's capacity for traumainformed practice by expanding existing work on therapeutic communities (Arnold et al., 2020; Báez et al., 2019; 
Longhi et al., 2019; Matlin et al., 2019; Pinderhughes et al., 2015; Tebes et al., 2019). The Sanctuary Model (Esaki et al., 2013) is a trauma-informed organizational change intervention based on the concept of therapeutic communities. These communities emphasize active and collective participation among stakeholders in creating a system of healing (Esaki et al., 2013). The Sanctuary Model is a blueprint for promoting positive clinical and organizational change that promotes safety and recovery through the creation of a trauma-informed community (Esaki et al., 2013).

\section{The Children's Resilience Initiative (CRI) in Walla Walla, Washington}

The CRI was launched in 2010 with the following goals: to educate the community of Walla Walla, Washington about ACEs and the science of brain development and to build community resilience (SAMHSA, 2017). This initiative involved engaging a coalition with community residents and stakeholders (e.g., schools, city government, law enforcement, health and social service providers) to identify their needs and challenges, increase public awareness of childhood trauma, and reshape programs, policies, and practices to be trauma-informed (SAMHSA 2017). Evaluation findings indicated that, in one high-school, after trauma-informed practices were implemented, students demonstrated increased resilience and academic achievement (SAMHSA, 2017). In addition, school disciplinary policies were transformed to emphasize student selfregulation practices, and teachers became more attuned to potential underlying causes of student problem behaviors (SAMHSA, 2017). Teams were also trained to help ensure the sustainability of CRI (SAMHSA, 2017). In short, this initiative was grounded in the principles of a traumainformed approach and, through its emphasis on community empowerment, helped to promote positive and sustained community-wide change (SAMHSA, 2017).

\section{Pottstown Trauma-Informed Community Connection (PTICC)}

The authors of this article were actively involved in the development, implementation, and evaluation of another community-based, trauma-informed initiative known as PTICC, which is the focus of the analyses presented herein. This initiative began in 2014, following the creation of the Pottstown Trauma Task Force, which consisted of representatives including early childhood providers, law enforcement officials, members of the faith community, and behavioral health and social service providers from the community of Pottstown, PA (see Matlin et al., 2019 for a more detailed description). The Task Force partnered with outside researchers and consultants and used an ongoing participatory process to conceptualize, implement, and translate PTICC (Matlin et al., 2019). The primary goal of this initiative was to build a trauma-informed community through training diverse stakeholders in the potential signs and symptoms of child trauma and how to create safe physical and emotional environments for children and families (PTICC Website, n.d.).

PTICC activities were guided by three work groups focused on building capacity in the following areas: education and training, communications, and networking (Matlin et al., 2019). Social and emotional learning (SEL) curricula were embedded within the Pottstown School District to strengthen children's competencies in self-regulation and to engage families (Matlin et al., 2019). SEL is focused on cultivating self-awareness, self-management, responsible decision-making, healthy relationship skills, and social awareness among students Collaborative for Academic, Social, and Emotional Learning (CASEL, 2021). In PTICC, SEL curricula were aligned with trauma-informed principles in support of the community initiative (Sichel et al., 2021).

PTICC participants were invited to complete trainings on ACEs, trauma, trauma-informed practice, SEL, and resilience (Matlin et al., 2019). During the initial phase of this initiative, a key objective was to enhance beliefs favorable to the use of trauma-informed practice; changes in the services network and related system supports for traumainformed practice would be introduced once key community stakeholders, such as education and community service providers, were trained. Early findings suggested that PTICC helped to enhance participants' knowledge about trauma-informed practice, which was essential to building a trauma-informed community (Matlin et al., 2019). One of the measures used was the Attitudes Related to TraumaInformed Care (ARTIC) Scale (Baker et al., 2016), which was based on an earlier measure developed to evaluate a staff trauma training model. The items were derived from key stakeholder feedback, expert opinions, and scholarly literature (Baker et al., 2016). The new measure has been validated with human health and service providers and school-based staff (Baker et al., 2016, 2021) and is an efficient and cost-effective measure of attitudes toward trauma-informed care.

\section{Methodological Challenges Associated with Community-Based Research}

Despite the community-wide benefits associated with the implementation of initiatives such as CRI and PTICC that aim to reduce adverse outcomes linked to ACEs and foster resilience, challenges exist in how to account for the dynamic impacts of such work on stakeholders. As noted by Longhi et al. (2019) in their assessment of the capacity 
building strategies used in Walla Walla, WA, too many factors may be at play to be easily measured and controlled in evaluations of such complex community initiatives in which "system changes rarely follow a logical sequential set of linear causal steps" (p. 15). In addition, non-experimental studies preclude inferences of causality, making it difficult to understand the impacts of complex initiatives on primary stakeholders (Longhi et al., 2019).

Other methodological considerations include the issue of ceiling effects, or when a high proportion of participants have maximum scores on the observed variable(s). The abilities of quantitative measures may be limited by their lack of variability and sensitivity and insufficient range of measurement, resulting in skewed scores (Andrew et al., 2011; McBee, 2010). Ceiling effects are often observed in the use of participant satisfaction scales (Andrew et al., 2011). It is feasible that community stakeholders who are committed to the values of trauma-informed practice and their enhancement at the onset of an intervention may not show meaningful growth on quantitative assessments of such a commitment over time because they had moderate to high average scores at the onset.

\section{Benefits of mixed-methods research}

Mixed-methods research can help to offset potential limitations associated with the use of quantitative measures (e.g., ceiling effects; Andrew et al., 2011). These methods involve collecting and analyzing qualitative and quantitative data within the same study, often from the same data sources (Creswell, 2009). Integrating qualitative and quantitative methodologies allows one method to clarify the other and can generate rich responses that complement or expand on quantitative findings (Aresi et al., 2017), or help explain them (Tebes and Kraemer 1991). For example, interviews or focus groups can provide insight into educators' successes and challenges in implementing traumainformed practices. Mixed-methods approaches are useful in assessing initiatives that involve multilevel systems (Wisdom \& Creswell, 2013) and can provide a nuanced understanding of how initiatives impact the community by triangulating data across sources and participant groups (Aresi et al., 2017). Scholars have recently called for more mixed-methods research to better understand traumainformed practices and contextual factors that influence their implementation (Mihelicova et al., 2018).

\section{Present Study}

The purpose of this study was to contribute to the growing research on trauma-informed communities by examining the views and experiences of two stakeholder groups involved in PTICC. As noted earlier, PTICC is a multilevel systems intervention that used a participatory process to build a trauma-informed community in Pottstown, PA. This three-year initiative engaged youth, families, community leaders, and representatives from various service sectors (e.g., education, health care, law enforcement) in trainings and activities to enhance their understandings of ACEs, trauma, trauma-informed practice, SEL, and resilience, and how to effectively respond to signs of traumatic stress, prevent further traumatization, and promote thriving. See Matlin et al. (2019) for a description of the PTICC implementation process and overall preliminary findings.

In this study, survey and focus group data from two specific groups of stakeholders (i.e., education and community partners) were analyzed to address the following research questions:

1. Did participants show increased favorable beliefs toward trauma-informed practice?

2. Did participants show increased favorable perceptions of the impacts of PTICC on their day-to-day use of trauma-informed practices and supports in the previous six months?

3. Based on analysis of focus group data, how did the groups describe the perceived impacts of PTICC? What were the similarities and differences between groups?

4. Based on analysis of the survey and focus group data together, what were the areas of convergence and divergence in participants' trauma-informed beliefs and perceived impacts of PTICC?

\section{Method}

This sample was derived from a longitudinal evaluation of a larger multilevel trauma-informed initiative that was conducted between 2016 and 2019 in partnership with the community of Pottstown, Pennsylvania. Only the method and results relevant to this study are presented.

\section{Participants}

\section{Survey Participants}

A total of 96 participants completed at least one survey over the course of the study. However, of these participants, 14 were excluded from the present analysis, given that they represented professional sectors that fell outside the categories of interest (i.e., arts, sports, and leisure; family; and religious) because they did not comprise a large proportion of the sample, resulting in a total of 82 participants. Of these 82 participants, $63(76.8 \%)$ were community partners from 
sectors in areas including business and philanthropy; government and law enforcement; health care; and social services. In addition, 19 (23.2\%) participants were staff from the Pottstown School District or outside organizations that provided educational services to children and families. Individual demographic data on participants were not collected, a limitation that is described in the Discussion section. Of the 82 participants, 50 provided survey data at more than one time point; 39 (78.0\%) were community partners; and $11(22.0 \%)$ were education partners.

\section{Focus Group Participants}

Convenience samples of school district staff and community partners were recruited to participate in two focus groups. A sample of parents/caregivers was also recruited to participate; however, given the small sample $(n=3)$ and limited survey data from this group, these data were excluded from this analysis. Members of the PTICC Steering Committee (including parents, community leaders, educators, providers) spread the word to PTICC participants about the opportunity to participate in focus groups and provided those interested with contact information for the researchers. Immediately prior to the focus groups, demographic information was collected from all participants using a brief questionnaire that was developed for the present study. One group of participants included community partners $(n=5$, Age Range $=20$ to 59 years) who worked in the fields of mental health, social services, and criminal justice. All partners (100\%) identified as female and as non-Latinx. The majority of participants (80.0\%) identified as White or European American.

The second group consisted of Pottstown School District staff ( $n=6$, Age Range $=20$ to 49 years), including principals. Half (50.0\%) of the sample was female, and all staff identified as non-Latinx (100\%). In addition, half (50.0\%) identified as White or European American and the other half as Black or African American.

\section{Procedure}

Individuals who attended at least one in-person PTICC meeting were invited to complete an online Semi-Annual Survey. Participants received an email link via Qualtrics to complete a 55-item survey that asked them about their current trauma-related knowledge, beliefs, and prior training and to report on their perceived impacts of PTICC on their behaviors in the previous six months. Over the course of the study, three surveys were administered across successive six-month periods (Time 1: January - June 2017; Time 2: July - December 2017; and Time 3: January - June 2018). Each survey took about $20 \mathrm{~min}$ to complete and participants received a $\$ 10$ gift card.
In December 2017, the focus groups were co-facilitated by the first, second, and third authors who used semi-structured protocols. The focus groups were conducted in a school conference room during the day and in the evening to accommodate participants' schedules. Participants signed assent forms immediately prior to participating. Each group took approximately $45 \mathrm{~min}$ to complete and food was provided to thank participants for their time. The groups were audio-recorded and transcribed by trained researchers. This study was approved by the University's Institutional Review Board and all participants provided informed consent.

\section{Measures}

\section{Survey Measures}

The semi-annual survey consisted of several scales that were analyzed in this study and are summarized below.

\section{Trauma-Informed Practice Beliefs}

Participants completed an adapted version of the ten-item Attitudes Related to Trauma-Informed Practice (ARTIC-10; Baker et al., 2016) scale and the five-item ARTIC-System Support subscale (Baker et al., 2016). Each item consisted of two statements that reflected more and less favorable beliefs toward trauma-informed practice. Participants indicated their beliefs by using a seven-point, Likert-type scale that reflected their belief at work in the past two months. Items included "Individuals I serve could act better if they really wanted to" versus "Individuals I serve are doing the best they can with the skills they have," and "Ups and downs are part of my work, so I don't take it personally" versus "The unpredictability and intensity of my work makes me think I'm not fit for this job." Items were recoded, as appropriate, and an overall mean score was calculated, such that higher scores indicated more favorable beliefs toward trauma-informed practice. Scores showed adequate reliability: Time $1(\alpha=$ $0.77)$, Time $2(\alpha=0.76)$, and Time $3(\alpha=0.77)$.

\section{Trauma-Informed Practice System Supports}

The ARTIC-System Support (ARTIC-SS) subscale (Baker et al., 2016) consisted of five items that used the same response rubric as the ARTIC-10. Items assessed participants' views of support they received in their workplaces for implementing trauma-informed practice. Items included "I have the support I need to work in a trauma-informed way" versus "My organization/group talks about trauma-informed practice, but it is really business as usual," and "I do not have enough support to implement trauma-informed practice" versus "I have enough support to implement traumainformed practice." Items were recoded, as appropriate, and 
an overall mean score was calculated, such that higher scores indicated more perceived organizational support for traumainformed practice. Scores showed adequate reliability: Time $1(\alpha=0.76)$, Time $2(\alpha=0.79)$, and Time $3(\alpha=0.73)$.

\section{Perceived Use of Trauma-Informed Practices and Supports}

Participants completed a six-item scale developed for use in this study that asked them to indicate to what extent PTICC influenced their use of trauma-informed practices and supports in the previous six months. The items were scored on a five-point, Likert-type scale, ranging from 1 (Not at all) to 5 (A great deal). An overall mean score was calculated, with higher scores indicating more favorable perceptions of PTICC's influences on their use of trauma-informed practices and supports. Items assessed self-perceived changes in respondents' knowledge of trauma (e.g., "To what extent have PTICC's efforts... improved your knowledge about trauma, ACEs, resilience, and healthy development?") and relevant actions (e.g., ... increased your application of traumainformed and adverse childhood experiences (ACEs) concepts in your work?). These items are consistent with the elements of a trauma-informed approach described in the Introduction section, which reflect knowledge and action (Hanson et al., 2018). Scores showed adequate reliability: Time $1(\alpha=0.88)$, Time $2(\alpha=0.85)$, and Time $3(\alpha=0.82)$.

\section{Focus Group Protocols}

The protocols were developed for this study and included eight questions that asked participants about their experiences in the initiative and its perceived impacts on their trauma-related knowledge, attitudes, and skills. Questions included "Please tell us how you got involved in PTICC," "What types of training or educational experiences have you participated in through your work or through PTICC about childhood trauma or adverse childhood experiences?," "What does it mean to you to be "traumainformed'?," and "How, if at all, has participating in PTICC changed how you work as a professional?"

\section{Analytic Strategy}

Descriptive statistics were tabulated for all of the quantitative measures. Given the relatively small sample of participants representing the Education sector $(n=19)$, no between-group analyses were conducted. Instead, paired sample $t$-tests were used to assess potential overall changes in participant scores on the ARTIC-10, ARTIC-SS, and Perceived Use of Trauma-Informed Practices and Supports measures. Each participant was assigned a unique Participant ID that allowed us to track their longitudinal data.
The data were analyzed using IBM SPSS Statistics Version 26 software.

In regard to the focus group data, the first and second authors conducted thematic analysis (TA; Braun \& Clarke, 2006) of participants' responses to assess their PTICC-related views and experiences. This method is appropriate for identifying and describing patterns or themes that emerge in qualitative data and for exploring an array of questions using inductive or deductive approaches (Braun \& Clarke, 2006). First, the authors fully immersed themselves in the data by independently reading and re-reading each transcript and making notes of themes that they observed. Next, they discussed their findings and transformed the themes into an initial set of codes that they summarized in separate codebooks for each participant group. Using the codebooks, they independently coded the transcripts and met to resolve any discrepancies in their coding decisions. Kappa coefficients indicated adequate interrater reliability: 0.82 for community partners and 0.77 for education partners. The data were analyzed using NVivo Version 12 software.

\section{Results}

\section{Quantitative Findings}

Table 1 summarizes descriptive statistics (overall and by participant group) for the following measures: ARTIC-10, ARTIC-SS, and Perceived Use of Trauma-Informed

Table 1 Descriptive statistics for ARTIC-10, ARTIC-SS, and perceived use of trauma-informed practices and supports by sample $(n=82)$

\begin{tabular}{|c|c|c|c|}
\hline \multirow[t]{2}{*}{ Measure } & \multicolumn{3}{|l|}{ Mean $(S D)$} \\
\hline & Time 1 & Time 2 & Time 3 \\
\hline Overall Sample & $(n=47)$ & $(n=59)$ & $(n=40)$ \\
\hline ARTIC-10 & $5.80(0.68)$ & $5.31(0.82)$ & $5.88(0.75)$ \\
\hline ARTIC-SS & $5.23(1.18)$ & $5.35(1.23)$ & $5.24(1.14)$ \\
\hline $\begin{array}{l}\text { Use of Trauma- } \\
\text { Informed Practices }\end{array}$ & $3.75(0.94)$ & $4.09(0.81)$ & $4.23(0.70)$ \\
\hline Community Partners & $(n=34)$ & $(n=48)$ & $(n=32)$ \\
\hline ARTIC-10 & $5.88(0.72)$ & $5.29(0.86)$ & $5.88(0.71)$ \\
\hline ARTIC-SS & $5.12(1.29)$ & $5.46(1.23)$ & $5.28(1.05)$ \\
\hline $\begin{array}{l}\text { Use of Trauma- } \\
\text { Informed Practices }\end{array}$ & $3.57(0.85)$ & $4.09(0.81)$ & $4.25(0.74)$ \\
\hline Education & $(n=13)$ & $(n=11)$ & $(n=8)$ \\
\hline ARTIC-10 & $5.58(0.52)$ & $5.38(0.61)$ & $5.90(0.93)$ \\
\hline ARTIC-SS & $5.51(0.76)$ & $4.85(1.12)$ & $5.10(1.52)$ \\
\hline $\begin{array}{l}\text { Use of Trauma- } \\
\text { Informed Practices }\end{array}$ & $4.32(0.99)$ & $4.08(0.87)$ & $4.17(0.54)$ \\
\hline
\end{tabular}

Note. ARTIC Attitudes Related to Trauma-Informed Care, PTICC Pottstown Trauma-Informed Community Connection 
Practices and Supports. As shown in the table, participants had moderate to high average scores on the three measures across the three time points.

\section{Changes in Beliefs Toward Trauma-Informed Practice}

A series of paired sample $t$-tests examined whether, in the overall sample, there were significant changes in participants' beliefs about trauma-informed practice, as measured by the ARTIC-10. Results are summarized in Table 2.

From Time 1 to Time 2, there was a significant decrease in trauma-informed beliefs. However, from Time 2 to Time 3 , there was a significant increase in participants' traumainformed beliefs. There was also a significant increase in belief scores from Time 1 to Time 3 .

\section{Changes in Trauma-Informed Practice Beliefs about Systems Supports}

Although no changes were expected in beliefs about trauma-informed practice related to systems supports so early in this initiative, we examined these data to gauge their empirical relationship to beliefs about traumainformed practice. In contrast to evidence of changes in beliefs about the use of trauma-informed practice, there was no significant increase in participants' perceptions of system supports for trauma-informed practice on the ARTIC-SS.

\section{Changes in Perceived Use of Trauma-Informed Practices and Supports}

A series of paired sample $t$-tests examined whether, in the overall sample, there were significant changes in participants' perceptions of their use of trauma-informed practices and supports in the previous six months. As shown in Table 2, findings indicated no significant changes from Time 1 to Time 2 , from Time 2 to Time 3 , or from Time 1 to Time 3 .

\section{Focus Group Findings}

Participants in both focus groups offered thoughtful observations about their PTICC involvement, what it had meant to them thus far, and challenges of becoming traumainformed. Four overarching themes emerged from the focus groups. First, and perhaps most important, education and community partners shared details about what it meant to them to be trauma-informed. Second, focus group participants described how becoming trauma-informed cultivated hope for the future. Third, many described benefits of trauma-related training through PTICC, but also the need
Table 2 Paired sample t-tests examining changes in ARTIC10, ARTIC-SS, and perceived use of trauma-informed practices and supports

\begin{tabular}{|c|c|c|c|c|c|}
\hline & Timepoint & Mean $(S D)$ & $t$ & $d f$ & $p$-value \\
\hline \multicolumn{6}{|l|}{ ARTIC-10 } \\
\hline \multirow[t]{2}{*}{ Pair $1(n=30)$} & ARTIC-10 Time 1 & $5.87(0.66)$ & 3.95 & 29 & 0.000 \\
\hline & ARTIC-10 Time 2 & $5.27(0.93)$ & & & \\
\hline \multirow[t]{2}{*}{ Pair $2(n=31)$} & ARTIC-10 Time 2 & $5.33(0.79)$ & -3.26 & 30 & 0.003 \\
\hline & ARTIC-10 Time 3 & $5.87(0.77)$ & & & \\
\hline \multirow[t]{2}{*}{ Pair $3(n=20)$} & ARTIC-10 Time 1 & $5.80(0.58)$ & -2.35 & 19 & 0.03 \\
\hline & ARTIC-10 Time 3 & $6.08(0.63)$ & & & \\
\hline \multicolumn{6}{|l|}{ ARTIC-SS } \\
\hline \multirow[t]{2}{*}{ Pair $1(n=30)$} & ARTIC-10 Time 1 & $5.18(1.17)$ & -0.55 & 29 & 0.59 \\
\hline & ARTIC-10 Time 2 & $5.27(1.33)$ & & & \\
\hline \multirow[t]{2}{*}{ Pair $2(n=31)$} & ARTIC-10 Time 2 & $1.22(5.30)$ & 0.78 & 30 & 0.44 \\
\hline & ARTIC-10 Time 3 & $5.16(1.14)$ & & & \\
\hline \multirow[t]{2}{*}{ Pair $3(n=20)$} & ARTIC-10 Time 1 & $5.30(1.10)$ & -1.13 & 19 & 0.28 \\
\hline & ARTIC-10 Time 3 & $5.51(1.22)$ & & & \\
\hline \multicolumn{6}{|c|}{ Perceived use of trauma-informed practices } \\
\hline \multirow[t]{2}{*}{ Pair $1(n=30)$} & ARTIC-10 Time 1 & $3.77(0.84)$ & -0.94 & 29 & 0.35 \\
\hline & ARTIC-10 Time 2 & $3.92(0.83)$ & & & \\
\hline \multirow[t]{2}{*}{ Pair $2(\mathrm{n}=31)$} & ARTIC-10 Time 2 & $4.16(0.63)$ & -0.64 & 30 & 0.53 \\
\hline & ARTIC-10 Time 3 & $4.25(0.58)$ & & & \\
\hline \multirow[t]{2}{*}{ Pair $3(n=20)$} & ARTIC-10 Time 1 & $3.92(0.66)$ & -0.49 & 19 & 0.63 \\
\hline & ARTIC-10 Time 3 & $4.0(0.74)$ & & & \\
\hline
\end{tabular}

Note. ARTIC Attitudes Related to Trauma-Informed Care, PTICC Pottstown Trauma-Informed Community Connection. 
Table 3 Summary of findings from focus groups with community partners $(n=5)$ and pottstown school district staff $(n=6)$

\begin{tabular}{|c|c|c|c|}
\hline \multirow[t]{2}{*}{ Theme } & \multicolumn{2}{|l|}{ Group } & \multirow[t]{2}{*}{ Example Quote } \\
\hline & $\begin{array}{l}\text { Community } \\
\text { Partners }\end{array}$ & $\begin{array}{l}\text { Pottstown } \\
\text { School } \\
\text { District Staff }\end{array}$ & \\
\hline \multicolumn{4}{|l|}{ What it Means to be Trauma-Informed } \\
\hline Reframing one's perspective. & $\mathrm{X}$ & $\mathrm{X}$ & $\begin{array}{l}\text { "...everyone's coming with their own level of baggage and their own histories, so } \\
\text { youhave to bear that in mind when somebody lashes out. It's not that they have an } \\
\text { issuewith you necessarily, but it's something within themselves that they're } \\
\text { strugglingwith or it's a reminder...being more aware of those triggers..." }\end{array}$ \\
\hline Being more self-reflective. & $\mathrm{X}$ & $\mathrm{X}$ & $\begin{array}{l}\text { "I think that the other interesting piece about it, for me, is how do we as practitioners } \\
\text { of whatever it is that we do, take on this conversation personally, so that we can } \\
\text { professionally be different." }\end{array}$ \\
\hline $\begin{array}{l}\text { Acquiring skills to respond more effectively } \\
\text { to others who have experienced trauma. }\end{array}$ & $\mathrm{X}$ & $\mathrm{X}$ & $\begin{array}{l}\text { "I've seen a change, a shift in how the teachers are responding to [students'] } \\
\text { behaviors. They're a little more calm, a little more understanding. Instead of } \\
\text { focusing on what [the students] did, they're more looking out for the triggers to try } \\
\text { and prevent those triggers from happening." }\end{array}$ \\
\hline A Sense of Hope for the Future & $\mathrm{X}$ & & $\begin{array}{l}\text { "I found that the community partners meetings are...energizing. For me, there's a } \\
\text { hope factor. A lot of the work that I've done....doesn't have a lot of hope. So, I think } \\
\text { part of it, for me, is that [the initiative] offers... a hope factor...that's tangible." }\end{array}$ \\
\hline $\begin{array}{l}\text { Perceived Benefits of Trauma-Related } \\
\text { Training }\end{array}$ & $\mathrm{X}$ & $\mathrm{X}$ & $\begin{array}{l}\text { "...the training...that's a three-part series [was my favorite aspect of the initiative]. } \\
\text { I'm now 'Trauma Competent' and I highly recommend [it]." }\end{array}$ \\
\hline Challenges in Getting Others to "Buy-In" & $\mathrm{X}$ & $\mathrm{X}$ & $\begin{array}{l}\text { "I tend to be the only person in my discipline at these different events. Even the } \\
\text { trauma training conference in Philly over the summer...I know it's a hard sell in my } \\
\text { discipline, but I didn't realize it would be quite as challenging." }\end{array}$ \\
\hline
\end{tabular}

for increased and ongoing training. And finally, participants spoke of the challenges of getting buy-in from various groups for a trauma-informed perspective. These findings are summarized in Table 3 and are described in detail below.

\section{What It Means to Become Trauma-Informed}

Focus group participants were most engaged when describing what it meant to be trauma-informed, and identified three components: (1) a shift in their perspective to include greater awareness and understanding of the potential signs of traumatic stress among children and adults; (2) a deeper understanding of their own adverse experiences, especially as children, that prompted reflection on how their own adverse experiences may have impacted their thoughts and interactions later in life; and (3) acquisition of skills and behaviors of how to thoughtfully respond to trauma in the context of their work or family.

\section{Trauma-informed means...reframing one's perspective -} For many, becoming trauma-informed meant reframing one's perspective on the world in critical ways. As one community partner stated:

I think [trauma-informed] means looking at a person and the people around them and the community in a very different lens. It's so absolutely important to see, you know, the whole... 'What's wrong with you?' How many times did we say that for a long time? Just reframing that and recognizing relationships.
Similarly, one school staff member described how being trauma-informed involved "looking below the surface":

...when you're looking at things through a trauma lens, you're not just looking at immediately what's in front of you. Like I love that iceberg illustration... you're looking at all of those things that are under the surface and those things that aren't around that add to the current state...

Community and education partners provided numerous examples of how they experienced (or witnessed in others) transformations in understanding trauma and its potential impacts on children's development. For instance, as noted by a community partner, "...I think by informing the families, I think this initiative is helping the families understand [trauma] and the teachers understand it." Similarly, as two school staff members stated: "[The initiative] really gives me an opportunity to build on past knowledge and to really grow and learn new things" and

I've learned from these children that they do have a lot of stuff going on at home and they freely tell me sometimes and that helps me to kind of put that lens on that says 'Okay, this is stuff that they're going through that's going to have an impact on the behaviors that they're having at school...so let me realize that when I'm speaking to them...

As each of these examples illustrates, becoming traumainformed involves opening a new window on the world, what 
one called a "trauma lens," that makes it difficult to return to previous personal and professional ways. This perspective includes a new language, shared by others who were traumainformed, about what was newly visible for the first time.

Trauma-informed means...being more self-reflective Community and education partners also indicated that being "trauma-informed" meant reflecting internally on how their own adverse experiences may have impacted their thoughts and interactions. One community partner described her experiences in PTICC as therapeutic: "It's almost been like a therapy for me, from stuff experienced in childhood, stuff experienced as an adult..." Similarly, as one school staff member stated when speaking about her own trauma experience in childhood: "I think that being able to understand how it actually did affect me and how [it may affect someone] whose had multiple experiences with something, that's significant."

The reflection among focus group participants that was prompted by describing what it meant to be trauma-informed was quite common, suggesting that becoming traumainformed can have both unintended positive and negative effects. Clearly, reflection on one's own traumatic experiences can trigger painful memories or a sense of loss due to the experience, but it can also foster greater understanding and empathy of others who may have experienced trauma.

Trauma-informed means...acquiring skills to respond more effectively to others who have experienced trauma School and community partners each described how PTICC helped them acquire skills and behaviors to respond more effectively to others, at work or in their family, who have experienced trauma. For example, several school staff described positive changes in teachers' reactions to problematic student behaviors. As one participant said:

...most of the lessons and the things that they talk about usually were happening moments after [an incident] had happened... where now,...teachers are teaching [the lesson] ahead of time and exposing students to it in the hopes that it's reinforcing when life presents itself...

Other participants also noted how the initiative positively impacted their own parenting practices. As one person said, "[the training] helps me to be more aware as a parent in addition to what I'm doing with my work..."

\section{A Sense of Hope for the Future}

A sentiment shared by individuals in the community partners group, with which all others agreed, was that the community partner meetings cultivated a sense of hope for the future. If, as noted above, becoming trauma-informed includes acquiring a deeper understanding of what it means to experience trauma and respond to it that is informed through self-reflection, it is not surprising that becoming trauma-informed can help cultivate a sense of hope for the future. One participant described how PTICC provided her with an underlying sense of hope that she, in collaboration with others, could help to improve the lives of individuals affected by trauma. In particular, she linked this favorable aspect of the initiative to the community engagement efforts, noting:

I found that the community partners meetings are... energizing. For me, there's a hope factor. A lot of the work that I've done...doesn't have a lot of hope. So, I think part of it, for me, is that [the initiative] offers...a hope factor...that's tangible.

\section{Perceived Benefits of Trauma-Related Training}

Participants in both groups identified the trauma-related training they received through PTICC as critical to becoming trauma-informed. One school staff member reflected on how the training appeared to be a useful tool for parents:

...what I found (is)... they're finding [the training] really helpful because what it has done is it's giving them insight not only into their child but also their own upbringing. And so it provides a tool that they would not have otherwise had.

In addition, as one parent shared, "I heard about ACEs and stuff like that at school, but it was super skated over. Your presentation gave me more than the school's, than like in college."

Participants in both groups also emphasized the need for more trainings and resources to enhance their own traumarelated knowledge and skills or those of others. Community partners described challenges associated with translating the more clinical-oriented trauma training that they received to individuals from non-clinical backgrounds. As one partner stated:

...aside from the mental health training that has happened, which I think is beneficial, but I'd like to see more, it's hard because I'm trained in trauma as a clinician, but then giving it to people who aren't...I don't know. I don't know if there can be something... not a better training, because I think it was good, but something a little bit stronger. 
Similarly, school staff discussed the need for more training targeted toward their teachers to aid them in actively applying what they learned. According to one school staff member:

...[the teachers] understand trauma...they understand why it's important, but...at least I feel like in our building, we're in the phase now of moving from 'Okay, we understand it' to making sure that we're putting it into practice...

\section{Challenges in Getting Others to "Buy-In"}

Both groups of focus group participants noted challenges in getting other adults to buy in to trauma-related training and activities, and their potential benefits. School staff described how some parents of their students took offense to training provided to their children in how to handle stressful and potentially traumatic situations. For instance, as one participant said, “... some parents were saying 'Well, you know, you're coming into my house, telling me how to raise my kid." School staff also discussed broader challenges associated with getting parents actively involved in PTICC. For instance:

I think we can always do more to engage parents and it's just always a challenge because, as we all know, the parents that we really want to get out and get the message to are not the ones that come out for a whole variety of reasons...

Similar challenges were described by school staff in the varied responses of parents to trauma-informed practices taking place in the schools:

...you have this group of parents that really love it and embrace it because it's like 'Oh wow, my kid's coming home and he's saying these things to me so I know that it's going throughout the school,' but then you have the other parents who take that firm stance 'Let me tell you something, son... This is my house and we're gonna follow my rules.' So that's where there's a little bit of conflict in it.

\section{Comparison of Survey and Focus Group Findings}

Analysis of the survey data found relatively favorable scores on participants' beliefs about trauma-informed practice and their perceived impacts of PTICC on their behaviors. These findings are largely in alignment with the positive PTICCrelated experiences described by participants in the focus groups. In the focus groups, although both groups described positive experiences, the school staff cited more concrete examples of how PTICC appeared to positively impact students, parents, and themselves (in their roles as both educators and as parents).

Based on the survey data, between Time 1 and Time 2, participants showed a significant decrease in their favorable beliefs about trauma-informed practice. This finding conflicts, in part, with feedback from the focus groups. Both groups described how the PTICC trainings enhanced their understandings of ACEs, how to recognize the signs and symptoms of child traumatic stress, and effectively respond. However, based on the survey data, favorable beliefs appeared to improve with time, as PTICC progressed. Focus group data still helped to elucidate some interventionrelated challenges that occurred during this time. For instance, both groups cited the need for more training in how to apply what they were learning to different scenarios. Perhaps these limitations of the training contributed to a decline in participants' endorsement of trauma-informed beliefs during the first half of the intervention.

\section{Discussion}

This study aimed to enhance understanding of the experiences of two key stakeholder groups, education and community partners, involved in a community-based traumainformed initiative, PTICC. The study used a mixedmethods approach to assess potential increases in participants' favorable beliefs toward trauma-informed practice and perceived impacts of PTICC on their behaviors. Overall, education and community participants reported moderate to high (or relatively favorable) scores in regard to these beliefs and perceived impacts of the intervention, with participants' beliefs appearing to become more favorable over time, as the intervention expanded within the community. As expected, there were no changes in participants' perceptions of organizational system support for traumainformed practice, given that groups were held less than one year into the initiative. Also, no changes were observed in participants' perceived impacts of PTICC, but this finding may have been because scores were already relatively high to begin with.

Qualitative focus group analyses complement these quantitative findings to provide rich, detailed information about participants' experiences in this community-wide initiative to promote the use of trauma-informed practice. Educators and community service providers identified several benefits of trauma-informed training and agreed that being "trauma-informed" meant reframing one's perspective, becoming more self-reflective, and acquiring skills to respond more effectively to those who have experienced 
trauma. Focus group participants also noted that being trauma-informed cultivated a sense of hope for the future. This finding is consistent with prior research on ACEs and resilience. Müller and Kenney (2021) discussed how professional workshops and trainings on childhood trauma have helped to "[reframe] the biology of early life adversity as a "science of hope"" (p. 1236) through emphasizing the potential for positive developmental change linked to supportive environments and relationships. However, focus group participants also identified challenges associated with becoming trauma-informed, including achieving buy-in from community partners, school staff, and parents. This finding aligns with prior research describing resistance that researchers and providers may encounter from youth, caregivers, and colleagues in response to trauma-informed work, which may be perceived as patronizing and radical (Isobel, 2016).

These findings enhance understanding of how diverse stakeholders experienced a dynamic and complex community-level intervention to promote trauma-informed practice, but also illustrate several important methodological considerations. These were described in brief in the Introduction section and are explored in greater depth below.

\section{Considerations for Future Community-Engaged Evaluation Research}

\section{Addressing Ceiling Effects}

In our work with PTICC, the community's commitment to building a network of support and becoming traumainformed was strikingly evident. In 2008, the Pottstown School District established an initiative, known as the Pottstown Early Action for Kindergarten Readiness (PEAK), in partnership with early childhood education programs to address the links between ACEs and school readiness (Matlin et al., 2019). This initiative helped to spread awareness of the effects of trauma on child development and laid a strong foundation for PTICC. Many of the education and community stakeholders involved in the conceptualization of PTICC drew from their earlier experiences with PEAK to help inform the design, delivery, and assessment of PTICC in collaboration with the research team. Given that messaging about ACEs had already permeated the community when PTICC launched, we anticipated that stakeholder buy-in to PTICC and the traumainformed principles it emphasized would be strong. Therefore, it was not surprising that survey respondents had high average scores on the constructs of interest at the onset of their participation. These initial high scores left little room to observe a sufficient range of responses in subsequent measurements.
The issue of ceiling effects is well-documented in the longitudinal research literature (e.g., Chyung et al., 2020; Fries et al., 2011; McBee, 2010). Of note, given the small sample in this study, we did not find it prudent to directly test for potential ceiling effects using methods such as the Tobit, or censored, regression model (McBee, 2010). However, it is recommended that researchers consider adequately testing for this measurement issue, particularly in community-engaged research in which the potential for ceiling effects is high. In addition, Chyung et al. (2020) suggested that increasing the number of survey response options and using fully labeled and positively packed scales may help to reduce the risk of ceiling effects.

\section{Disaggregating Data}

A limitation of our study was the size and scope of the longitudinal sample and unbalanced number of participants in the education and community partner sectors. As a result, we did not have rich enough data to permit analysis of individual-level trajectories in a large group beyond two time points of data collection and were unable to test for potential between-group differences in trauma-informed beliefs and perceived impacts of PTICC. Although these data can help to paint an initial picture of findings, this study would have benefitted from assessment of data from a larger group over a more extended period of time to allow for assessment of individual growth that may not yet have occurred by the second data collection point. Given the Pottstown School District's role as a long-time and key stakeholder in the community, we might expect significant differences between school staff members' commitment to trauma-informed beliefs and that of smaller and newer groups to the initiative (e.g., those sub-groups that comprised our Community Partners sample). It is recommended that future community-engaged research on traumainformed practice consider disaggregating data by sites or groups to uncover more meaningful and varied patterns of outcomes while avoiding more generalized analytical approaches (Tirrell et al., 2021). It would also be helpful to follow-up with individuals who discontinue their participation in similar initiatives to learn potential barriers to participation and how to improve retention.

\section{Mitigating Challenges Associated with Participant Recruitment and Buy-in}

As noted earlier, we experienced challenges in recruiting large samples of diverse community partners and parents/ caregivers in our study. Focus group findings helped to reveal potential reasons for their lower engagement in PTICC. For instance, one community partner from the field of criminal justice stated that trauma-informed practice was 
a "hard sell" in her discipline, which tends to be more punitive-oriented. School staff also stated that some parents were hesitant to become involved in PTICC for fear of being labeled as a "bad parent" or being "taught how to parent."

These findings emphasize the need to adequately identify and attend to potential stakeholder concerns at the onset of a community-based intervention and to prioritize efforts to build trust and camaraderie with all groups. Building and maintaining trust is an essential component of communitybased participatory research (Christopher et al., 2008) and, in our study, perhaps more attention could have been focused on engaging with PTICC's Family Advisory Committee to identify and mitigate potential barriers to parent/caregiver participation.

In addition, we experienced challenges in retaining a longitudinal sample of participants across groups. Although participants were invited to provide survey data at three time points, many discontinued their participation after the second data collection, for reasons unknown. Perhaps it would have been helpful to follow-up with this sub-group to better understand their reasons for discontinuing their participation. In addition, it would have been informative to recollect quantitative and qualitative data at least six months post-intervention to assess whether any outcomes were sustained, which was not possible due to limited resources.

\section{Implications for Community Capacity Building}

This study underscores the importance of building "collaborative capacity" in community coalition work to promote trauma-informed systems change (Foster-Fishman et al., 2001; Matlin et al., 2019). Collaborative capacity refers to the conditions that help a coalition to facilitate collaboration and sustained positive community change (Foster-Fishman et al., 2001). These conditions include member capacity (e.g., knowledge, skills, motivation), relational capacity (e.g., shared vision, power sharing), organizational capacity (e.g., effective leadership, communication), and programmatic capacity (e.g., clear and feasible goals) (Foster-Fishman et al., 2001).

In the context of PTICC, a Steering Committee, or coalition, comprised of consultants/researchers and local leaders in education, social and behavioral health services, philanthropy, and law enforcement played an instrumental role in building capacity across these domains through an ongoing participatory process (Matlin et al., 2019). This group formed a shared vision around building a traumainformed community and connected with key members throughout the community (e.g., from the school district) to spread awareness of ACEs and trauma-informed practice (Matlin et al., 2019). In particular, working groups focused on building member capacity (e.g., though the delivery of trainings on ACEs and resilience) and relational capacity (e.g., through fostering cross-sectoral collaboration on trauma-informed) and helped to translate the vision of the Steering Committee into action, as reinforced by the study's findings (Matlin et al., 2019).

This community capacity building process mirrors that described in the Children's Resilience Initiative (CRI) in Walla Walla, Washington (Longhi et al., 2019), as described earlier. Similarly to PTICC, the success of CRI was driven by the "iterative interplay" of several key elements of capacity building, including the formation of a small group of community leaders who identified a common vision and goals and helped to facilitate cross-sectoral collaboration and the sustainment of trauma-informed processes and principles (Longhi et al., 2019). This work involved shifts in knowledge, skills, and mindsets; the formation of trusting and collaborative relationships; and changes in organizational policies and practices (Longhi et al., 2019).

We recommend that future community-engaged work prioritizes strengthening member, relational, organizational, and programmatic capacities to empower communities to effect systems change (Foster-Fishman et al., 2001). This process starts with building a clearly defined and shared vision and facilitating cross-sectoral collaboration to infuse this vision across organizations and enact it (Matlin et al., 2019).

Trauma during childhood has the potential to adversely affect one's physical, cognitive, emotional, and social development across the life span. However, traumainformed approaches have the potential to buffer young people and their families against adverse events by enhancing awareness and understanding of the signs and impacts of childhood trauma and how to effectively prevent retraumatization and foster resilience. Findings from our mixed-methods study of PTICC help to elucidate what it means to be trauma-informed, positive gains of participation in a community-based, trauma-informed initiative, and various implementation challenges for such initiatives. We discuss findings in the context of key methodological considerations for future community-engaged work seeking to build trauma-informed communities and present recommendations for building community capacity for change.

Acknowledgements This work was supported, in part, by the Pottstown School District, The Scattergood Foundation, Yale School of Medicine, and the National Institute on Drug Abuse (T32DA019426; Tebes, PI). We are grateful to Laurie Kolka and the Pottstown School District, and the Pottstown Trauma-Informed Community Connection (PTICC) steering committee and community partners. We also thank colleagues at The Consultation Center at Yale and The Scattergood Foundation for their assistance, including: Aly Ferguson, Susan Florio, Caitlin O'Brien, and Samantha Pittenger.

\section{Compliance with Ethical Standards}

Conflict of Interest The authors declare no competing interests. 
Publisher's note Springer Nature remains neutral with regard to jurisdictional claims in published maps and institutional affiliations.

\section{References}

Andrew, S., Salamonson, Y., Everett, B., Halcomb, E. J., \& Davidson, P. M. (2011). Beyond the ceiling effect: Using a mixed methods approach to measure patient satisfaction. International Journal of Multiple Research Approaches, 5, 52-63.

Aresi, G., Henderson, D. X., Hall-Campbell, N. F., \& Ogley-Oliver, E. J. F. (2017). Practicing community psychology through mixed methods participatory research designs. The Journal of New Paradigm Research, 73(7), 473-490.

Arnold, K. T., Pollack Porter, K. M., Frattaroli, S., Durham, R. E., Mmari, K., Clary, L. K., \& Mendelson, T. (2020). Factors that influenced adoption of a school-based trauma-informed universal mental health intervention. Prevention Science, 21, 1081-1092.

Báez, J. C., Renshaw, K. J., Bachman, L. E. M., Kim, D., Smith, V. D., \& Stafford, R. E. (2019). Understanding the necessity of trauma-informed care in community schools: A mixed-methods program evaluation. Children \& Schools, 41(2), 101-110.

Baker, C. N., Brown, S. M., Overstreet, S., \& Wilcox, P. D. (2021). Validation of the Attitudes Related to Trauma-Informed Care Scale (ARTIC). Psychological Trauma: Theory, Research, Practice, and Policy, 13(5), 505-513.

Baker, C. N., Brown, S. M., Wilcox, P. D., Overstreet, S., \& Arora, P. (2016). Development and psychometric evaluation of the Attitudes Related to Trauma-Informed Care (ARTIC) Scale. School Mental Health: A Multidisciplinary Research and Practice. Journal, 8(1), 61-76.

Bloom, S. L. (2013). Creating sanctuary: Toward the evolution of sane societies. New York, NY: Routledge.

Braun, V., \& Clarke, V. (2006). Using thematic analysis in psychology. Qualitative Research in Psychology, 3(2), 77-101.

Bridgland, V. M. E., Moeck, E. K., Green, D. M., Swain, T. L., Nayda, D. M., Matson, L. A., Hutchison, N. P., \& Takarangi, M. K. T. (2021). Why the COVID-19 pandemic is a traumatic stressor. PLoS One. https://doi.org/10.1371/journal.pone.0240146.

Chang, X., Jiang, X., Mkandarwire, T., \& Shen, M. (2020). Associations between adverse childhood experiences and health outcomes in adults aged 18-59 years. PLOS ONE, 14(2), e0211850.

Christopher, S., Watts, V., McCormick, A. K., \& Young, S. (2008). Building and maintaining trust in a community-based participatory research partnership. American Journal of Public Health, 98 (8), 1398-1406.

Chyung, S. Y., Hutchinson, D., \& Shamsy, J. A. (2020). Evidencebased survey design: Ceiling effects associated with response scales. Performance Improvement, 59(6), 6-13.

Collaborative for Academic, Social, and Emotional Learning (CASEL) (2021). SEL: What are the core competence areas and where are they promoted? https://casel.org/sel-framework/.

Creswell, J. W. (2009). Research design: Qualitative, quantitative, and mixed methods approaches. 3rd ed. Thousand Oaks, CA: Sage Publications.

DeCandia, C. J., Guarino, K., \& Clervil, R. (2014). Trauma-informed care and trauma-specific services: A comprehensive approach to trauma intervention. American Institutes for Research. https://www.air.org/sites/default/files/downloads/report/TraumaInformed\%20Care\%20White\%20Paper_October\%202014.pdf.

Esaki, N., Benamati, J., Yanosy, S., Middleton, J. S., Hopson, L. M., Hummer, V. L., \& Bloom, S. L. (2013). The Sanctuary Model: Theoretical framework. Families in Society: The Journal of Contemporary Social Services, 94(2), 87-95.
Foster-Fishman, P. G., Berkowitz, S. L., Lounsbury, D. W., Jacobson, S., \& Allen, N. A. (2001). Building collaborative capacity in community coalitions: A review and integrative framework. American Journal of Community Psychology, 29(2), 241-261.

Fries, J., Rose, M., \& Krishnan, E. (2011). The PROMIS of better outcome assessment: Responsiveness, floor and ceiling effects, and internet administration. The Journal of Rheumatology, 38(8), $1759-1764$.

Hanson, R. F., Lang, J. M., Fraser, J. G., Agosti, J. R., Ake, G. S., Donisch, K. M., \& Gewirtz, A. H. (2018). Trauma-informed care: Definitions and statewide initiatives. In J. B. Klika, \& J. R. Conte (Eds), The APSAC handbook on child maltreatment (4th edn., pp. 272-291). Thousand Oaks, CA: SAGE.

Harris, M., \& Fallot, R. (2001). Using trauma theory to design service systems. New Directions for Mental Health Services, 89. Jossey Bass.

Isobel, S. (2016). Trauma informed care: A radical shift or basic good practice? Australian Psychiatry, 24(6), 589-591.

Krystal, J. H., Alvarado, J., Ball, S. A., Fortunati, F. G., Hu, M., Ivy, M. E., Kapo, J., Olson, K. D., Rohrbaugh, R. M., Sinha, R., Tebes, J. K., Vender, R. J., Yonkers, K. A., Mayes, L. C., \& Mayes, L. C. (2021). Mobilizing an institutional supportive response for healthcare workers and other staff in the context of COVID-19: The Yale experience. General Hospital Psychiatry, $68,12-18$.

Longhi, D., Brown, M., Barila, T., Fromm Reed, S., \& Porter, L. (2019). How to increase community-wide resilience and decrease inequalities due to adverse childhood experiences (ACEs): Strategies from Walla Walla, Washington. Journal of Prevention \& Intervention in the Community, 9, 1-17.

Magruder, K. M., McLaughlin, K. A., \& Bornon, D. L. E. (2017), Trauma is a public health issue. European Journal of Psychotraumatology, 8(1), 1375338. https://doi.org/10.1080/20008198. 2017.1375338.

Matlin, S. L., Champine, R. B., Strambler, M. J., O’Brien, C. O., Hoffman, E., Whitson, M., Kolka, L., \& Tebes, J. K. (2019). A community's response to adverse childhood experiences: Building a resilient, trauma-informed community. American Journal of Community Psychology, 64(3-4), 451-466.

McBee, M. (2010). Modeling outcomes with floor or ceiling effects: An introduction to the Tobit Model. Gifted Child Quarterly, 54 (4), 314-320.

Middleton, J. S., Bloom, S. L., Strolin-Goltzman, J., \& Caringi, J. (2019). Trauma-informed care and the public child welfare system: The challenges of shifting paradigms: Introduction to the special issue on trauma-informed care. Journal of Public Child Welfare, 13(3), 235-244.

Mihelicova, M., Brown, M., \& Shuman, V. (2018). Trauma-informed care for individuals with serious mental illness: An avenue for community psychology's involvement $\mathrm{n}$ community mental health. American Journal of Community Psychology, 61, 141-152.

Müller, R., \& Kenney, M. (2021). A science of hope? Tracing emergent entanglements between the biology of early life adversity, trauma-informed care, and restorative justice. Science, Technology, \& Human Values, 46(6), 1230-1260.

National Institute of Mental Health (NIMH). 2017. Post-traumatic stress disorder. https://www.nimh.nih.gov/health/statistics/posttraumatic-stress-disorder-ptsd.shtml.

Pinderhughes, H., Davis, R. A., \& Williams, M. (2015). Adverse community experiences and resilience: A framework for addressing and preventing community trauma. Kaiser Permanente. https://www.preventioninstitute.org/publications/adversecommunity-experiences-and-resilience-framework-addressing-a nd-preventing. 
Pottstown Trauma-Informed Community Connection (PTICC). (n.d.). https://pottstownmatters.org/.

Scheer, J. R., \& Poteat, V. P. (2018). Trauma-informed care and health among LGBTQ intimate partner violence survivors. Journal of Interpersonal Violence. https://doi.org/10.1177/0886260518820688.

Sichel, C., Strambler, M. J., Matlin, S., Garcia, \& Tebes, J. K. (2021). Integrating school climate and trauma-informed practice: An empirical proof of concept. (Under review)

Sowder, K. L., Knight, L. A., \& Fishalow, J. (2018). Trauma exposure and health: A review of outcomes and pathways. Journal of Aggression, Maltreatment \& Trauma, 27(10), 1041-1059.

Stolbach, B. C., \& Anam, S. (2017). Racial and ethnic health disparities and trauma-informed care for children exposed to community violence. Pediatric Annals, 46(10), e377-e381.

Substance Abuse and Mental Health Services Administration (SAMHSA). (July 2014). SAMHSA's concept of trauma and guidance for a trauma-informed approach. SAMHSA's Trauma and Justice Strategic Initiative. https://ncsacw.samhsa.gov/ userfiles/files/SAMHSA_Trauma.pdf.

Substance Abuse and Mental Health Services Administration (2017). Spotlight: Building resilient and trauma-informed communities. Walla Walla, WA: Mobilizing the community for resilience. https://store.samhsa.gov/product/Spotlight-Building-Resilient-a nd-Trauma-Informed-Communities-Walla-Walla-WAMobilizing-the-Community-for-Resilience/SMA17-5020.
Substance Abuse and Mental Health Services Administration (SAMHSA). (2020). Understanding child trauma. https://www.sa mhsa.gov/child-trauma/understanding-child-trauma.

Tebes, J. K., Champine, R. B., Matlin, S. L., \& Strambler, M. J. (2019). Population health and trauma-informed practice: Implications for programs, systems, and policies. American Journal of Community Psychology, 64(3-4), 494-508.

Tebes, J. K., \& Kraemer, D. T. (1991). Quantitative and qualitative knowing in mutual support research: Some lessons from the recent history of scientific psychology. American Journal of Community Psychology, 19(5), 739-756.

Temkin, D., Harper, K., Stratford, B., Sacks, V., Rodriguez, Y., \& Bartlett, J. D. (2020). Moving policy toward a whole school, whole community, whole child approach to support children who have experienced trauma. Journal of School Health, 90(12), 940-947.

Tirrell, J. M., Gansert, P. K., Dowling, E. M., Williams, K., Iraheta, G., Lerner, J. V., King, P. E., Sim, A. T. R., \& Lerner, R. M. (2021). Interrogating ergodicity and specificity in youth development programs in El Salvador. Journal of Applied Developmental Psychology, 73, 101243.

Wisdom, J., \& Creswell, J. W. (2013). Mixed methods: Integrating quantitative and qualitative data collection and analysis while studying patient-centered medical home models. AHRQ Agency for Healthcare Research and Quality. https://pcmh.ahrq.gov/page/ mixed-methods-integrating-quantitative-and-qualitative-datacollection-and-analysis-while. 